\title{
Comprehensive Model Toward Optimization of SAG In-rich InGaN Nanorods by Hydride Vapor Phase Epitaxy
}

\author{
Hadi Hijazi ${ }^{1, *}$, Mohammed Zeghouane ${ }^{2, *}$, Jihen Jridi ${ }^{2}$, Evelyne Gil ${ }^{1,2}$, Dominique Castelluci ${ }^{2}$, \\ Vladimir G. Dubrovskii ${ }^{3}$, Catherine Bougerol ${ }^{4}$, Yamina André ${ }^{1,2}$, Agnès Trassoudaine ${ }^{2}$ \\ ${ }^{1}$ ITMO University, Kronverkskiy pr. 49, 197101 St. Petersburg, Russia \\ ${ }^{2}$ Université Clermont Auvergne, CNRS, SIGMA Clermont, Institut Pascal, F-63000 Clermont-Ferrand, France \\ ${ }^{3}$ St. Petersburg State University, Universitetskaya Emb. 13B, 199034, St. Petersburg, Russia \\ ${ }^{4}$ Université Grenoble Alpes, CNRS, Institut Néel, 38000 Grenoble France
}

E-mail:*hijazi@itmo.ru, mohammed.zeghouane@uca.fr

Received xxxxxx

Accepted for publication $\mathrm{xxxxxx}$

Published xxxxxx

\begin{abstract}
Controlled growth of In-rich InGaN nanowires/nanorods has long been considered as a very challenging task. Here, we present the first attempt to fabricate InGaN nanorods by selective area growth using HVPE (hydride vapor phase epitaxy). It is shown that InGaN nanorods with different indium contents up to $90 \%$ can be grown by varying the In/Ga flow ratio. Furthermore, nanowires are observed on the surface of the grown nanorods with a density that is proportional to the Ga content. The impact of varying the $\mathrm{NH}_{3}$ partial pressure is investigated to suppress the growth of these nanowires. It is shown that the nanowire density is considerably reduced by increasing the $\mathrm{NH}_{3}$ content in the vapor phase. We attribute the emergence of the nanowires to the final step of growth occurring after stopping the $\mathrm{NH}_{3}$ flow and cooling down the substrate. This is supported by a theoretical model based on the calculation of the supersaturation of the ternary InGaN alloy in interaction with the vapor phase as a function of different parameters assessed at the end of growth. It is shown that the decomposition of the InGaN solid alloy indeed becomes favorable below a critical value of the $\mathrm{NH}_{3}$ partial pressure. The time needed to reach this value increases with increasing the input flow of $\mathrm{NH}_{3}$, and therefore the alloy decomposition leading to the formation of nanowires becomes less effective. These results should be useful for fundamental understanding of the growth of InGaN nanostructures and may help to control their morphology and chemical composition required for device applications.
\end{abstract}

Keywords: InGaN nanorods, HVPE, selective area growth, model.

\section{Introduction}

Group III-nitride semiconductors are very important materials for optoelectronic devices [1-3]. In particular, ternary InGaN alloys are used as active layers in highly efficient light-emitting diodes (LEDs) and laser structures in a wide wavelength range from infrared (IR) to ultraviolet (UV) [4-6]. The development of InGaN based devices for longer wavelengths is however admittedly challenging. Synthesis of homogenous and high quality InGaN thin films with high In compositions is difficult due to surface segregation of In occurring via the spinodal decomposition at the usual growth temperatures [7-11]. Furthermore, the large lattice mismatch between InGaN and the underlying substrate results in a high residual strain in the material. This leads to the alloy clustering causing carrier localization with a significant increase of non-radiative defect density. These factors limit the performance of devices based on planar structures [12-15]. 1D structures show interesting 
properties such as efficient dislocation-free strain relaxation and may help to extend the compositional range of $\mathrm{InGaN}$ on lattice-mismatched substrates. $\mathrm{InGaN} / \mathrm{GaN}$ core-shell nanowires (NWs) are particularly promising for high efficiency red LEDs with a lower defect density and higher light extraction efficiency compared to planar devices [16]. Consequently, synthesis of InGaN NWs by either catalyst-assisted or catalyst-free growth methods have recently gained much attention. InGaN NWs are grown by different epitaxy techniques such as molecular beam epitaxy (MBE) [17-22], metal-organic vapor phase epitaxy (MOVPE) [16,23-26] and hydride vapor phase epitaxy (HVPE) [27,28]. However, even in NWs one should compromise between high In content, spatial homogeneity of the alloy and crystal quality. Furthermore, random nucleation process leads to inhomogeneity of the NW lengths and diameters which induces the corresponding spread in electrical and optical properties of structures based on large ensembles of NWs. Selective area growth (SAG) of NWs in preselected and spatially organized locations allows one to improve the size homogeneity over a sample.

InGaN/GaN heterostructured NWs, or nanorods (NRs), have been reported in Ref. [29]. Recently, Bi et al. have demonstrated the growth of relaxed InGaN platelets with a maximum InN content of $18 \%$, suitable as templates for red micro-LEDs [30]. To the best of our knowledge, there have been no reports on SAG of high aspect ratio In-rich InGaN NRs with controlled In content and morphology. Here, we present the first attempt to grow such structures by HVPE. We study the effect of the growth conditions, particularly partial pressures of In and Ga precursors, on the morphology and composition of InGaN NRs and provide a model to explain different experimental observations. The results reported herein allow for a better control of the morphology of InGaN nanostructures by HVPE, and provide information about NWs growth trends as a function of the vapor phase composition useful for other epitaxy techniques.

\section{Experimental}

InGaN NRs were grown in a homemade horizontal HVPE reactor operating at atmospheric pressure. The reactor is composed of several zones that can be heated independently by an external furnace. In the first zone, the $\mathrm{InCl}_{3}$ gaseous precursor was produced by sublimation of $\mathrm{InCl}_{3}$ powder heated at $485^{\circ} \mathrm{C}$. The $\mathrm{GaCl}$ gaseous precursor was obtained by reaction of gaseous $\mathrm{HCl}$ with a liquid metallic $\mathrm{Ga}$ source placed in the second zone and heated at $670{ }^{\circ} \mathrm{C}$. $\mathrm{InCl}_{3}$ was then transported through an inner tube while $\mathrm{GaCl}$ was driven by a $\mathrm{N}_{2}$ carrier gaz to the downstream mixing zone, where the $\mathrm{NH}_{3}$ input flow $\left(\mathrm{F}_{\mathrm{NH}_{3}}^{\mathrm{i}}\right.$ in sccm) was directly injected. The substrates were $\mathrm{GaN} / \mathrm{c}-\mathrm{Al}_{2} \mathrm{O}_{3}$ templates covered with patterned $\mathrm{SiN}_{\mathrm{x}}$ layer where circular apertures were lithographically defined having a diameter of $200 \mathrm{~nm}$ and a pitch of $2 \mu \mathrm{m}$. The substrates were placed in the adjacent downstream growth zone where the vapor phase was assumed to be homogeneous.

Solid III-V ternary alloys grow by incorporation of III-V binaries at different rates, $\mathrm{GaN}$ and $\mathrm{InN}$ in the present case [31-35]. InN and GaN binaries are grown by HVPE at very different temperatures, $610-660^{\circ} \mathrm{C}$ and $900-1000{ }^{\circ} \mathrm{C}$ respectively. This makes growth of $\mathrm{InGaN}$ alloys by HVPE quite difficult. Obviously, InGaN NRs must be grown at an intermediate temperature which should ensure a compromise between a good selectivity, crystal quality and InN stability [31,32]. After several experiments, the optimal growth temperature was selected at $660{ }^{\circ} \mathrm{C}$. The growth time was fixed at 15 minutes.

As-grown samples with NRs were imaged by Carl Zeiss Supra scanning electron microscope (SEM) with an acceleration voltage of $3 \mathrm{kV}$. This SEM setup is coupled with an energy dispersive X-ray spectroscopy (EDX) analyzer that allows for an estimation of the average chemical compositions of as-grown structures. Images of individual NRs and the corresponding EDX maps were obtained in a transmission electron microscope (TEM). The acceleration voltage used for these measurements was $30 \mathrm{kV}$.

\section{Results and discussion}

InGaN nanorods were synthesized on Ga-polar $\mathrm{GaN} / \mathrm{c}-\mathrm{Al}_{2} \mathrm{O}_{3}$ substrate and grew along the (1000) direction. The structure and composition of these NRs are strongly influenced by the composition of the vapor. We define $r$ as the ratio between the $\mathrm{GaCl}$ input flow and the total element III flow, that is $r=\frac{F_{\mathrm{GaCl}}}{\mathrm{F}_{\mathrm{GaCl}}+\mathrm{F}_{\mathrm{InCl}_{3}}}$. We first explore the impact of $r$ on the morphology and chemical composition of the NRs. Typical SEM images after 15 min-growth at different $r$ are shown in Figure 1, along with the average compositions given in the insets. In this series of samples, the partial pressure of $\mathrm{NH} 3\left(\mathrm{P}_{\mathrm{NH}_{3}}\right)$ was fixed at $1.82 \times 10^{-1}$ atm (according to a previous study [28]). The only parameter that changed between the three samples was the ratio $\mathrm{r}$ (by changing the $\mathrm{GaCl}$ input flow) which was fixed at $0.93,0.85$ and 0.61 . The images in Figure 1 reveal the following trends. First, the absence of parasitic growth on the mask surface confirms the perfect selectivity of growth at the selected 

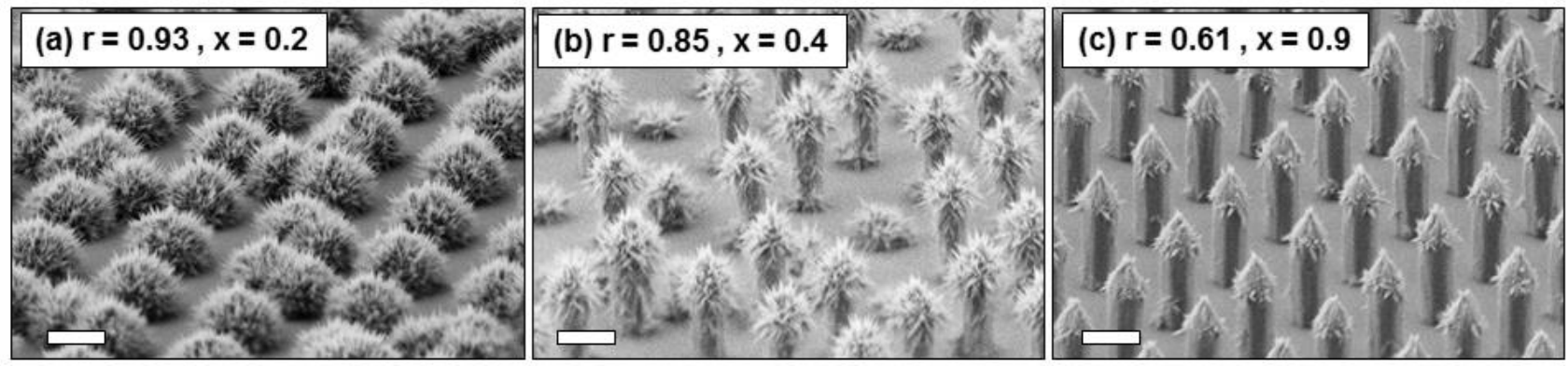

Figure 1: SEM images showing the morphology of InGaN NRs grown at $660{ }^{\circ} \mathrm{C}$ and $\mathrm{P}_{\mathrm{NH}_{3}}=1.82 \times 10^{-1}$ atm for 15 min at (a) $r=0.93$, (b) $r=0.85$, and (c) $r=0.61$. The corresponding V/III ratios are $2.35 \times 10^{2}, 3.80 \times 10^{2}$ and $2.73 \times 10^{2}$, respectively. The average indium contents $\mathrm{x}$ in the entire samples are given in the insets. Scale bar represents $1 \mu \mathrm{m}$.

temperature of $660{ }^{\circ} \mathrm{C}$. Second, the average indium content $\mathrm{x}$ (determined by EDX on as-grown samples) in InGaN NRs can be tuned by the vapor phase composition, with lower $\mathrm{r}$ resulting in higher $\mathrm{x}$. Third, the average length of the NRs increases with decreasing r. This result is expected from the growth rates of $\mathrm{GaN}$ and $\mathrm{InN}$ : InN growth rate is higher than $\mathrm{GaN}$ growth rate at given experimental parameters [31-35]. Fourth, NWs are present on the surface of the NRs, especially at their tips. The density of these NWs is higher for larger r. Note that any possible influence of the V/III ratio change on the surface morphology can be excluded since, as given in the caption of the Fig.1, the value of the V/III ratio is always very high. The contribution of surface diffusion of group III adatoms can also be excluded as it is negligible in HVPE process [28,32].

In order to reduce the density of such NWs and obtain a more regular morphology, we varied $\mathrm{P}_{\mathrm{NH}_{3}}$ between $0.69 \times 10^{-1}$ and $2.78 \times 10^{-1} \mathrm{~atm}$ at a fixed $\mathrm{r}$ of 0.93 (Samples NR1 to NR5). SEM images showing the evolution of the NRs morphology with $\mathrm{P}_{\mathrm{NH}_{3}}$ are presented in Figure 2. Growth selectivity was preserved in all cases. The NWs density decreases with increasing $\mathrm{P}_{\mathrm{NH}_{3}}$. The magnified TEM images of individual NRs shown in the yellow and green frames in panels (c) and (e) are given in panels (f-1) and (h-1) respectively. To check the homogeneity of the chemical composition, EDX elemental mapping was performed along the axis of these NRs. The maximum penetration depth of electrons in a solid $\operatorname{In}_{0.85} \mathrm{Ga}_{0.15} \mathrm{~N}$ of density $6.7 \mathrm{~g} . \mathrm{cm}^{-3}$ is about $d_{\max }=3 \mu \mathrm{m}$ for the acceleration voltage used $(30 \mathrm{kV})$. Therefore, the diffracted $\mathrm{X}$-ray signal is generated at a depth $d \leq d_{\max }$, which depends on (i) the ionization energy of the line considered (K or L) and (ii) the absorption of X-ray in the sample. In order to collect the signals of In and Ga from the same depth, we have selected the $\mathrm{L}$ and $\mathrm{K}$ lines. The NRs tips correspond to zero distance, as shown by the yellow and green arrows in panels (f-1) and (h-1). The measured EDX profiles of NR3 and NR5 are shown in panels (f-2) and (h-2), respectively. Figure 2 (g-1) presents the magnified TEM image of individual NW (shown in the blue frame in panel (f-1)). Figure 2 (g-2) shows the EDX map of the same NW.

Despite the apparent differences in morphology, NR3 and NR5 show some common features. They have tapered tips where the indium content is lower than in the rest of the NRs, as observed in Figures 2 (f-2) and (h2). The indium content is further reduced in NR3 compared to NR5 due to the contribution of NWs, whose composition is close to stoichiometry $(\mathrm{x} \sim 0.5)$ (see Fig. 2 (g-2)). The average indium content in NR5 $(\sim 90 \%)$ is only slightly increased with respect to NR3 $(\sim 85 \%)$, suggesting that the value of $\mathrm{P}_{\mathrm{NH}_{3}}$ has a little impact on the chemical composition of the NRs. Another common property of the NRs is their hexagonal shape at the base which transitions to the round shape at a certain distance from the substrate due to roughening of the sidewalls induced by material decomposition. The main difference between NR3 and NR5 is the formation of NWs on NR3. Conical shapes of these NWs and their different chemical composition, which always stays around $\mathrm{x} \sim$ 0.5 regardless of the NRs composition, suggest that the NW growth mechanism is different from the one of the NRs. Based on the above observations, we attribute the formation of NWs to the decomposition of solid $\mathrm{InGaN}$ in the final step of growth, which finally leads to the 

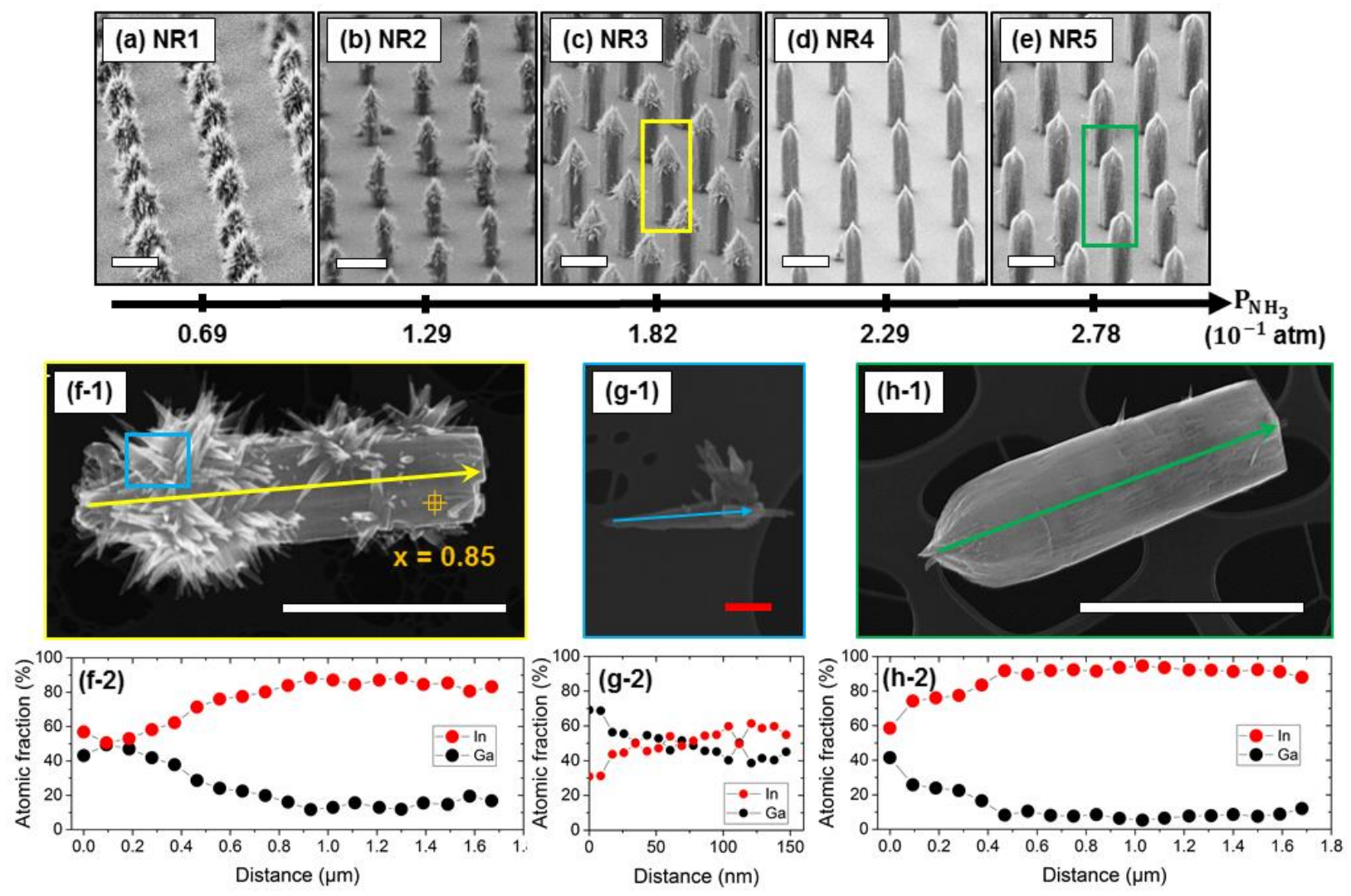

Figure 2: (a-e) SEM images of InGaN NRs in samples NR1 to NR5 grown at a fixed $r=0.61$ and different $\mathrm{P}_{\mathrm{NH}_{3}}$ increasing from $0.69 \times 10^{-1}$ to $2.78 \times 10^{-1}$ atm. The corresponding V/III ratios are $1.56 \times 10^{2}, 2.90 \times 10^{2}$, $4.09 \times 10^{2}, 5.14 \times 10^{2}$ and $6.35 \times 10^{2}$, respectively. The average indium content $\mathrm{x}$ in all bulk NRs is almost the same, about 0.85-0.9. (f-1) and (h-1) Magnified TEM images of the selected individual NRs shown in panels (c) and (e), respectively. (f-2) and (h-2) EDX maps of the same NRs. (g-1) TEM image of the selected NW shown in panel (f-1), with its EDX map shown in panel (g-2). White and red scale bars represent $1 \mu \mathrm{m}$ and 50 $\mathrm{nm}$, respectively.

formation of liquid metallic droplets under insufficient supply of $\mathrm{NH}_{3}$. More precisely, we suggest the following growth picture. Under our HVPE growth conditions, Inrich NRs grow first selectively by the vapor-solid (VS) mechanism [31-33] (step 1 in Figure 3). The $\mathrm{NH}_{3}$ and $\mathrm{GaCl}$ input flows are then switched off at the moment of time $\mathrm{t}=\mathrm{t}_{\text {off }}$ and the samples are rapidly cooled down. When decreasing the temperature, the equilibrium constant related to the formation of solid $\mathrm{GaN}\left(\mathrm{K}_{\mathrm{GaN}}\right)$ increases and that of $\operatorname{InN}\left(\mathrm{K}_{\mathrm{InN}}\right)$ decreases [32], so the tips of the NRs should be Ga-rich as shown by the EDX maps in Figures 2 (f-2) and (h-2). The total growth rate of the solid decreases with increasing the gallium content, leading to tapering of the NR tips observed in Figure 2 (step 2 in Figure 3). The residual $\mathrm{NH}_{3}$ flow $\left(\mathrm{F}_{\mathrm{NH}_{3}}^{\mathrm{r}}\right)$ decreases continuously from its input value
$\mathrm{F}_{\mathrm{NH}_{3}}^{\mathrm{i}}$ during the NRs growth [37]. This results in a decrease of the corresponding partial pressure $\mathrm{P}_{\mathrm{NH}_{3}}$ in the growth zone. The decreasing rate of $\mathrm{P}_{\mathrm{NH}_{3}}$ requires special dynamic simulations due to the complex inner geometry of the HVPE reactor, which is beyond the scope of this work. Solid InGaN stays stable as long as $\mathrm{P}_{\mathrm{NH}_{3}}$ is larger than a critical value $\mathrm{P}_{\mathrm{NH}_{3}}^{\mathrm{S}}$ required for condensation at a positive supersaturation of the vapor with respect to the solid. Once $\mathrm{P}_{\mathrm{NH}_{3}}^{\mathrm{S}}$ is reached, the decomposition of the solid begins (step 3 in Figure 3). The decomposition occurs by thermal dissociation of interatomic bonds in the solid. The $\mathrm{N}$ atoms start to desorb as $\mathrm{N}_{2}$ dimers, while the group III atoms start to form liquid droplets on the surface. Due to the high 


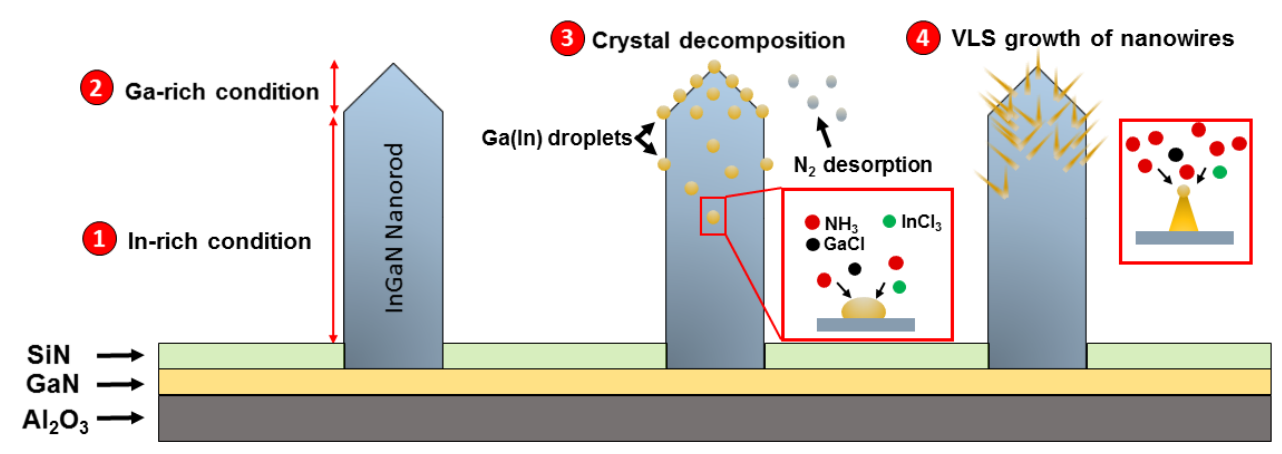

Figure 3: Schematic representation of the different steps involved in the growth of InGaN NR/NW: (1) - SAG of regular In-rich NRs by the VS mechanism; (2) - growth of Ga-rich tapered NR tips during cooling down; (3) - decomposition of the crystal at low $\mathrm{P}_{\mathrm{NH}_{3}}$, which produces liquid droplets; (4) - VLS growth of NWs.

volatility of In atoms compared to Ga [27,28], the liquid droplets are most likely Ga-rich. This explains (i) the increase in the NW density with the average GaN content in the NRs (Figure 1), and (ii) the higher NW density closer to the NR tips where the Ga concentration is locally higher than in the rest of the NRs (Figure 2 (f1)).

With the residual $\mathrm{NH}_{3}$ and $\mathrm{GaCl}$ gas, together with the continuous supply of $\mathrm{InCl}_{3}$ which is thermally produced inside the reactor, the liquid droplets continue to receive the growth species from the vapor. Therefore, we switch from the VS-type SAG growth of NRs to the vaporliquid-solid (VLS) growth of NWs. This VLS growth continues because the residual growth species are still present in the vapor phase (step 4 in Figure 3). Note that $\mathrm{F}_{\mathrm{NH}_{3}}^{\mathrm{i}}$ cannot be maintained at the end of growth since, when combined with $\mathrm{F}_{\mathrm{InCl}_{3}}^{\mathrm{i}}$, it leads to the formation of parasitic solid InN that can be deposited on the whole sample [28].

\section{Theoretical model}

We now turn to a more quantitative investigation of the $\operatorname{In}_{\mathrm{x}} \mathrm{Ga}_{1-\mathrm{x}} \mathrm{N}$ NRs decomposition leading to the formation of NWs at the end of growth. For this, we need to calculate the supersaturation of $\operatorname{In}_{x} \mathrm{Ga}_{1-x} \mathrm{~N}\left(\gamma_{\operatorname{In}_{x} G_{1-x} N}\right)$ and study its dependence on the relevant growth parameters. Let us first consider the equilibrium constants for forming solid $\mathrm{GaN}$ and $\mathrm{InN}$ pairs that mix to produce a ternary solid alloy. The incorporation of $\mathrm{GaN}$ and InN pairs into the solid proceeds via the following reactions:

$$
\begin{aligned}
& \mathrm{GaCl}_{\mathrm{g}}+\mathrm{NH}_{3 \mathrm{~g}} \rightleftharpoons \mathrm{GaN}_{\mathrm{s}}+\mathrm{HCl}_{\mathrm{g}}+\mathrm{H}_{2 \mathrm{~g}} \\
& \mathrm{InCl}_{3 \mathrm{~g}}+\mathrm{NH}_{3_{\mathrm{g}}} \rightleftharpoons \mathrm{InN}_{\mathrm{s}}+3 \mathrm{HCl}_{\mathrm{g}}
\end{aligned}
$$

Here, the subscripts $g$ and $s$ stand for the gaseous and solid phases, respectively. The equilibrium constants of these reactions can be calculated as follows:

$$
\begin{aligned}
& \mathrm{K}_{\mathrm{GaN}}=\exp \left(-\frac{\Delta \mathrm{G}_{\mathrm{GaN}}}{\mathrm{k}_{\mathrm{B}} \mathrm{T}}\right) \\
& \text { with } \Delta \mathrm{G}_{\mathrm{GaN}}=\Delta \mathrm{G}_{\mathrm{GaN}}^{0}+\mathrm{k}_{\mathrm{B}} \operatorname{Tln}(1-\mathrm{x})+\Omega_{\mathrm{s}} \mathrm{x}^{2} \\
& \mathrm{~K}_{\mathrm{InN}}=\exp \left(-\frac{\Delta \mathrm{G}_{\mathrm{InN}}}{\mathrm{k}_{\mathrm{B}} \mathrm{T}}\right) \\
& \text { with } \Delta \mathrm{G}_{\mathrm{InN}}=\Delta \mathrm{G}_{\mathrm{InN}}^{0}+\mathrm{k}_{\mathrm{B}} \operatorname{Tln}(\mathrm{x})+\Omega_{\mathrm{s}}(1-\mathrm{x})^{2}
\end{aligned}
$$

Here, $\mathrm{T}$ is the absolute temperature, $\mathrm{k}_{\mathrm{B}}$ is the Boltzmann constant, $\Delta \mathrm{G}_{\alpha}^{0}$ is the standard Gibbs free energy to form the pair $\alpha(\alpha=\mathrm{GaN}$ or $\mathrm{InN})$, which can be calculated using the tabulated thermodynamic data related to these growth species [36]. We use the regular solution model for the solid InGaN alloy, with $\mathrm{x}$ as the indium content in the alloy, and $\Omega_{\mathrm{s}}$ as the binary interaction parameter between $\mathrm{GaN}$ and InN pairs [38]. 


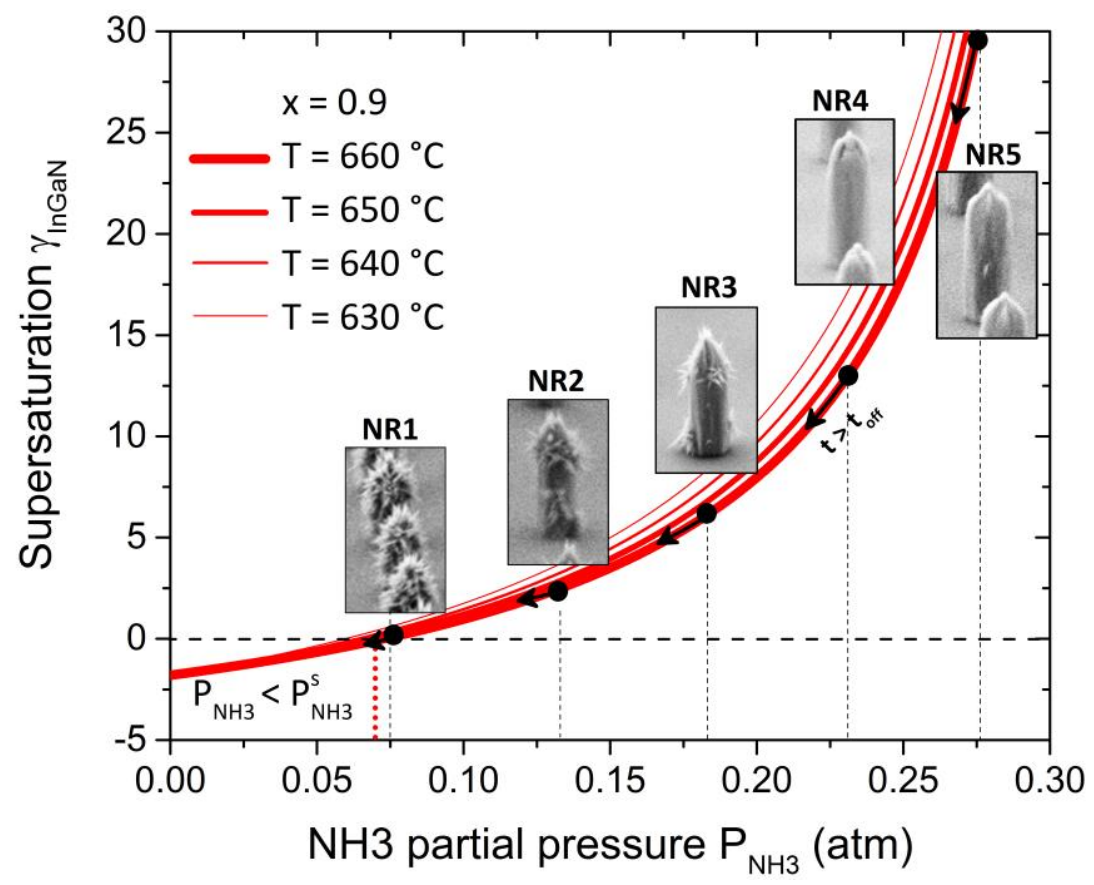

Figure 4: Evolution of $\gamma_{\mathrm{In}_{0.9} \mathrm{Ga} a_{0.1} \mathrm{~N}}$ with $\mathrm{P}_{\mathrm{NH}_{3}}$ in the final step of growth. The calculated supersaturation is shown for different temperatures T. SEM images represent the individual NR1 to NR5 grown at different initial pressures $\mathrm{P}_{\mathrm{NH}_{3}}^{\mathrm{i}}$ (labelled by the black dots). At $\mathrm{t}>\mathrm{t} \mathrm{off}, \mathrm{P}_{\mathrm{NH}_{3}}$ starts to decrease, as represented by the black arrows. The lengths of these arrows correspond to the decreasing rates of $\mathrm{F}_{\mathrm{NH}_{3}}^{\mathrm{r}}$. Thermal decomposition of solid InGaN occurs when $\mathrm{P}_{\mathrm{NH}_{3}}$ becomes lower than $\mathrm{P}_{\mathrm{NH}_{3}}^{\mathrm{S}}$, which is represented by the red dotted line.

The respective supersaturations of reactions (1a) and (1-b) are given by:

$$
\begin{aligned}
& \gamma_{\mathrm{GaN}}=\frac{\mathrm{P}_{\mathrm{GaClg}_{\mathrm{g}}} \mathrm{P}_{\mathrm{NH}_{3 \mathrm{~g}}} \mathrm{~K}_{\mathrm{GaN}}}{\mathrm{P}_{\mathrm{HClg}_{\mathrm{g}} \mathrm{P}_{\mathrm{H}_{2} \mathrm{~g}}(1-\mathrm{x}) \mathrm{a}_{\mathrm{GaN}_{\mathrm{S}}}}}-1, \\
& \gamma_{\mathrm{InN}}=\frac{\mathrm{P}_{\mathrm{InCl}_{\mathrm{g}}} \mathrm{P}_{\mathrm{NH}_{3 \mathrm{~g}}} \mathrm{~K}_{\mathrm{InN}}}{\mathrm{P}_{\mathrm{HClg}}^{3} \mathrm{Xa}_{\mathrm{InN}}}-1 .
\end{aligned}
$$

The chemical activities in the solid state, $\mathrm{a}_{\mathrm{GaN}_{\mathrm{s}}}$ and $\mathrm{a}_{\mathrm{InN}_{\mathrm{s}}}$, can be expressed within the regular solution model as:

$$
\begin{aligned}
& \mathrm{a}_{\mathrm{GaN}_{\mathrm{s}}}=\exp \left(\frac{\Omega_{\mathrm{S}} \mathrm{x}^{2}}{\mathrm{k}_{\mathrm{B}} \mathrm{T}}\right), \\
& \mathrm{a}_{\mathrm{InN}_{\mathrm{s}}}=\exp \left(\frac{\Omega_{\mathrm{S}}(1-\mathrm{x})^{2}}{\mathrm{k}_{\mathrm{B}} \mathrm{T}}\right) .
\end{aligned}
$$

Since the solid $\operatorname{In}_{\mathrm{x}} \mathrm{Ga}_{1-\mathrm{x}} \mathrm{N}$ is composed of $\mathrm{GaN}$ and $\mathrm{InN}$ pairs, its supersaturation can be calculated using the weighted supersaturations of binaries as follows:

$$
\gamma_{\mathrm{In}_{\mathrm{x}} \mathrm{Ga}_{1-\mathrm{x}} \mathrm{N}}=(1-\mathrm{x}) \gamma_{\mathrm{GaN}}+\mathrm{x} \gamma_{\mathrm{InN}}
$$

For growth of $\operatorname{In}_{x} \mathrm{Ga}_{1-\mathrm{x}} \mathrm{N}$ in the complex chemical HVPE process, the partial pressures of the different species in the vapor are interdependent through coupled reactions $[27,28]$. This should be accounted for when calculating the dependence of $\gamma_{\mathrm{In}_{\mathrm{X}} \mathrm{Ga}_{1-\mathrm{x}} \mathrm{N}}$ on the variable partial pressures. In our experimental conditions during SAG of NRs, both $\gamma_{\text {GaN }}$ and $\gamma_{\text {InN }}$ remain greater than unity, meaning that the chemical potentials of the vapor species are greater than the chemical potentials of the solid and the products of the reaction $[27,28]$.

However, during the cooling down step, a decrease of $\mathrm{P}_{\mathrm{NH}_{3}}$ has a significant impact on these supersaturations which decrease continuously until $\gamma_{\mathrm{In}_{\mathrm{X}} \mathrm{Ga}_{1-\mathrm{x}} \mathrm{N}}$ becomes negative at $\mathrm{P}_{\mathrm{NH}_{3}}=\mathrm{P}_{\mathrm{NH}_{3}}^{\mathrm{S}}$. The evolution of $\gamma_{\mathrm{In}_{0.9} \mathrm{Ga}_{0.1} \mathrm{~N}}$ with $\mathrm{P}_{\mathrm{NH}_{3}}$ for temperatures varying between $630{ }^{\circ} \mathrm{C}$ and $660^{\circ} \mathrm{C}$ are shown in Figure 4. Given the very slight dependence of $\gamma_{\mathrm{In}_{0.9} \mathrm{Ga}_{0.1} \mathrm{~N}}$ on $\mathrm{T}$, its impact on the formation of NWs can be neglected. Therefore, only $\mathrm{T}=660^{\circ} \mathrm{C}$ will be considered further to analyze the experimental observations. The SEM images 
show the individual NRs from different samples (NR1 to NR5) grown at different $\mathrm{P}_{\mathrm{NH}_{3}}$, which are represented by black dots. The decrease of $\mathrm{P}_{\mathrm{NH}_{3}}$ at $t>t_{\text {off }}$ is represented by black arrows, whose lengths are proportional to the decreasing rate of $\mathrm{F}_{\mathrm{NH}_{3}}^{\mathrm{r}}$. The critical pressure $\mathrm{P}_{\mathrm{NH}_{3}}^{\mathrm{S}}$ corresponding to zero supersaturation of In $\mathrm{GaN}$ is shown by the red dotted line.

We can now compare the partial pressures during growth of different NRs to the critical pressure. For NR1, $\mathrm{P}_{\mathrm{NH}_{3}}^{\mathrm{i}}$ is very close to $\mathrm{P}_{\mathrm{NH}_{3}}^{\mathrm{S}}$, therefore $\gamma_{\mathrm{InGaN}}$ is only slightly larger than zero. The growth of such NRs proceeds under near-equilibrium conditions, meaning that the time $\Delta \mathrm{t}$ required to reach $\mathrm{P}_{\mathrm{NH}_{3}}^{\mathrm{S}}$ after switching off the $\mathrm{NH}_{3}$ flow is very short. The decomposition of solid InGaN at the tip of NR1 starts early. On the other hand, the decreasing rate of the gas out of the reactor is quite low due to a low $\mathrm{P}_{\mathrm{NH}_{3}}^{\mathrm{i}}$, which is why the vapor phase provides the sufficient supply of group $\mathrm{V}$ atoms for a relatively long time $\left(t_{V L S}\right)$. This results in the high density of NWs observed on NR1. The time $\Delta \mathrm{t}$ becomes gradually longer with increasing $\mathrm{P}_{\mathrm{NH}_{3}}^{\mathrm{i}}$, meaning that the solid decomposition is less efficient, therefore the NW growth time $t_{V L S}$ gets increasingly shorter. This explains the lower NWs density present on NR2 and NR3, followed by their almost complete disappearance on NR4 and NR5 grown at even higher $\mathrm{P}_{\mathrm{NH}_{3}}^{\mathrm{i}}$, where we only observe the roughening of the surface induced by a soft decomposition of solid InGaN (Figure 2 (h-1)).

\section{Conclusion}

In conclusion, we have presented the first attempt to grow In-rich InGaN NRs by SAG HVPE. It has been shown that $\operatorname{In}_{\mathrm{x}} \mathrm{Ga}_{1-\mathrm{x}} \mathrm{N}$ NRs with different and controlled compositions $\mathrm{x}$ up to 0.9 can be obtained by varying the $\mathrm{In} / \mathrm{Ga}$ flow ratio. However, some irregular NWs have been observed on the NR tips. Despite the potential advantages of such structures for sensing applications, their presence is prohibitive for optoelectronic devices. The effect of the partial pressure of $\mathrm{NH}_{3}$ has been investigated to control the growth of these NWs. We found that much more NWs formed at low $\mathrm{P}_{\mathrm{NH}_{3}}$, while higher $\mathrm{P}_{\mathrm{NH}_{3}}$ yielded more regular morphologies with almost no NWs. This effect has been attributed to lower supersaturations of the vapor at lower $\mathrm{P}_{\mathrm{NH}_{3}}$, yielding

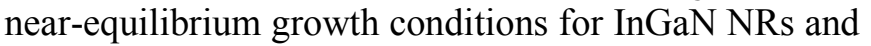
faster decomposition of the solid in the cooling down step after switching off the nitrogen input.
Decomposition of InGaN at the NR tips leads to the formation of liquid metallic droplets catalyzing the NW growth in the VLS mode. This explains the presence of NWs on the tips of InGaN NRs grown at lower $\mathrm{P}_{\mathrm{NH}_{3}}$ and their absence at higher $\mathrm{P}_{\mathrm{NH}_{3}}$. A model of the growth thermodynamics of InGaN NRs and NWs by HVPE quantifies and explains experimental findings.

Acknowledgments: Financial support received from the CNRS (PRC1300 CNRSJSPS) and from the GaNeX program of the French ANR agency (ANR-11-LABX-0014) is gratefully acknowledged. This work was also funded by the program "Investissements d'avenir" of the French ANR agency, the French government IDEX-SITE initiative 16HIDEX-0001 (CAP20-25), the European Commission (Auvergne FEDER Funds), and the Region Auvergne in the framework of the LabEx IMobS3 (ANR-10- LABX-16-01), CPER and Pack ambition recherche; Convention n ${ }^{\circ} 17011236$ 01- 61617. The authors thank 2MAtech, Aubière, France, for scanning electron microscopy measurements. HH and VGD thank the Russian Science Foundation for financial support under the Grant 19-72-30004.

Conflicts of interest: The authors declare no conflict of interest

\section{References:}

[1] Schubert E F Light-Emitting Diodes, $3^{\text {rd }}$ ed., Cambridge University Press, 2012.

[2] Ee Y K, Biser J M, Cao W, Chan H M, Vinci R P and Tansu N 2009 Metalorganic Vapor Phase Epitaxy of III-Nitride Light-Emitting Diodes on Nanopatterned AGOG Sapphire Substrate by Abbreviated Growth Mode. IEEE J. Sel. Top. Quantum Electron. 15 10661072.

[3] Krames M R, Shchekin O B, Mueller-Mach R, Mieller G O, Zhou L, Harbers G and Craford G 2007 Status and future of high-power light-emitting diodes for solid-state lighting J. Disp. Technol. 3 160-175.

[4] Nakamura S, Senoh M, Nagahama S I, Iwasa N, Yamada T, Matshusita T, Kiyoku $\mathrm{H}$ and Sugimoto $\mathrm{Y}$ 1996 InGaN-Based Multi-Quantum-Well-Structure Laser Diodes. Jpn. J. Appl. Phys. 35 74-76. 
[5] Arif R A, Ee Y K and Tansu N 2007 Polarization engineering via staggered InGaN quantum wells for radiative efficiency enhancement of light emitting diodes. Appl. Phys. Lett. 91091110.

[6] Zhao H, Liu G, Zhang J, Poplawsky J D, Dierolf V and Tansu N 2011 Approaches for high internal quantum efciency green InGaN light-emitting diodes with large overlap quantum wells Optics Express. 19 A991A1007.

[7] Ho I and Stringfellow G B 1996 Solid phase immiscibility in GaInN. Appl. Phys. Lett. 692701.

[8] Valdueza-Felip S, Bellet-Amalric E, NúñezCascajero A, Wang Y, Chauvat M-P, Ruterana P, Pouget S, Lorenz K, Alves E and Monroy E 2014 High Incontent InGaN layers synthesized by plasma-assisted molecular-beam epitaxy: Growth conditions, strain relaxation, and In incorporation kinetics. J. Appl. Phys. 116233504.

[9] Singh R, Doppalapudi D, Moustakas T D and Romano L T 1997 Phase separation in InGaN thick films and formation of InGaN/GaN double heterostructures in the entire alloy composition. Appl. Phys. Lett. 701089.

[10] Sughara T, Hao M, Wang T, Nakagawa D, Nao Y, Nishino K and Sakai S 1998 Role of Dislocation in InGaN Phase Separation. Jpn. J. Appl. Phys. 37 L1195L1198.

[11] Ponce F A, Srinivasan S, Bell A, Geng L, Liu R, Stevens M, Cai J, Omiya H, Marui H and Tanaka S 2003 Microstructure and electronic properties of $\mathrm{InGaN}$ alloys. Phys. Stat. Sol. (b) 240 273-284.

[12] Ju J, Loitsch B, Stettner T, Schuster F, Stutzmann $M$ and Koblmüller G 2014 Trade-off between morphology, extended defects, and compositional fluctuation induced carrier localization in high Incontent InGaN films. J. Appl. Phys. 116, 053501.
[13] Jones C M, Teng C H, Yan Q, Ku P-C and Kioupakis E 2017 Impact of carrier localization on recombination in InGaN quantum wells and the efficiency of nitride light-emitting diodes: Insights from theory and numerical simulations. Appl. Phys. Lett. 111 113501.

[14] Dawson P, Schulz S, Oliver R A, Kappers M J and Humphreys C J 2016 The nature of carrier localisation in polar and nonpolar InGaN/GaN quantum wells. $J$. Appl. Phys. 119181505.

[15] Armstrong A M, Bryant B M, Crawford M H, Koleske D D, Lee S R and Wierer Jr J 2015 Defectreduction mechanism for improving radiative efficiency in InGaN/GaN light emitting diodes using InGaN underlayers. J. Appl. Phys. 117134501.

[16] Ebaid M, Kang J H, Yoo Y S, Lim S H, Cho Y H and Ryu S W 2015 Vertically aligned InGaN nanowires with engineered axial In composition for highly efficient visible light emission. Scientific Reports 517003.

[17] Wu K M, Pan Y and Liu C 2009 InGaN nanorod arrays grown by molecular beam epitaxy: Growth mechanism structural and optical properties. Appl. Surf. Sci. 255 6705-6709.

[18] Vajpeyi A P, Ajagunna A O, Tsagaraki K, Androulidaki M and Georgakilas A 2009 InGaN nanopillars grown on silicon substrate using plasma assisted molecular beam epitaxy. Nanotechnology 20 325605 .

[19] Tabata T, Paek J, Honda Y Yamaguchi M and Amano H 2012 Growth of InGaN nanowires on a (111)Si substrate by RF-MBE. Phys. Status Solidi (C) 9 646-649.

[20] Nag D, Sarkar R, Bhunia S, Aggarwal T, Ghosh K, Sinha S, Ganguly S, Saha D, Horng R H and Laha A 2020 Role of defect saturation in improving optical response from InGaN nanowires in higher wavelength regime. Nanotechnology 31495705. 
[21] Hestroffer K., Lund C, Li H, Keller S, Speck J S and Mishra U K 2016 Plasma-assisted molecular beam epitaxy growth diagram of InGaN on (0001)GaN for the optimized synthesis of InGaN compositional grades. Phys. Status Solidi B 253 626-629.

[22] Zhang X, Lourenço-Martins H, Meuret S, Kociak $\mathrm{M}$, Haas B, Rouvière J L, Jouneau P H, Bougerol C, Auzelle T, Jalabert D, Biquard X, Gayral B and Daudin B 2016 InGaN nanowires with high InN molar fraction: growth, structural and optical properties. Nanotechnology 27195704.

[23] Kuo H C, Oh T S and Ku P-C 2013 MOCVD growth of vertically aligned InGaN nanowires. J. Cryst. Growth 370 311-313.

[24] Ra Y H, Rashid R T, Liu X, Lee J and Mi Z 2017 Scalable Nanowire Photonic Crystals: Molding the Light Emission of InGaN. Adv. Funct. Mater. 271702364.

[25] Cai X M, Leung Y H, Cheung K Y, Tam K H., Djurisic A B, Cie M H, Chen H Y and Gwo S 2006 Straight and helical InGaN core-shell nanowires with a high In core content. Nanotechnology 17 2330-2333.

[26] Ye F, Cai X M, Wang X M and Xie E Q 2007 The growth and field electron emission of $\mathrm{InGaN}$ nanowires J. Cryst. Growth 304 333-7.

[27] Roche E, André Y, Avit G, Bougerol C, Castelluci D, Réveret F, Gil E, Médard F, Leymarie J, Jean T, Dubrovskii V G and Trassoudaine A 2018 Circumventing the miscibility gap in InGaN nanowires emitting from blue to red. Nanotechnology 29465602.

[28] Zeghouane M, Avit G, André Y, Bougerol C, Yoann R, Ferret P, Castelluci D, Gil E, Dubrovskii V G, Amano H, Trassoudaine A 2018 Compositional control of homogeneous InGaN nanowires with the In content up to $90 \%$. Nanotechnology 30044001.

[29] Albert S, Bengoechea-Encabo A, Kong X, SanchezGarcia M A, Trampert A and Calleja E 2015 Correlation among Growth Conditions, Morphology, and Optical
Properties of Nanocolumnar InGaN/GaN Heterostructures Selectively Grown by Molecular Beam Epitaxy. Cryst. Growth Des. 15 2661-2666.

[30] Bi Z, Lu T, Colvin J, Sjögren E, Vainorius N, Gustafsson A, Johansson J, Timm R, Lenrick F, Wallenberg R, Monemar B and Samuelson L 2020 Realization of Ultrahigh Quality InGaN Platelets to be Used as Relaxed Templates for Red Micro-LEDs $A C S$ Appl. Mater. Interfaces 12 17845-17851.

[31] Zeghouane M, Avit G, Cornelius T W, Salomon D, André Y, Bougerol C, Taliercio T, Meguekam-Sado A, Ferret P, Castelluci D, Gil E, Tournié E, Thomas O and Trassoudaine A 2019 Selective Growth of Ordered Hexagonal InN Nanorods. CrystEngComm 21 2702-2708.

[32] Zeghouane M, Avit G, André Y, Taliercio T, Ferret P, Gil E, Castelluci D, Disseix P, Leymarie J and Trassoudaine A 2020 Morphological Control of InN Nanorods by Selective Area Growth-Hydride VaporPhase Epitaxy. Cryst. Growth Des. 20 2232-2239.

[33] Zeghouane M, André Y, Avit G, Jridi J, Bougerol C, Coulon P M, Ferret P, Castelluci D, Gil E, Shields P, Dubrovskii V G and Trassoudaine A 2020 Formation of voids in selective area growth of $\mathrm{InN}$ nanorods in $\mathrm{SiNx}$ on GaN templates. Nano Futures 4025002.

[34] Avit G, Zeghouane M, André Y, Castelluci D, Gil E, Baé S Y, Amano H and Trassoudaine A 2018 Crystal engineering by tuning the growth kinetics of GaN 3-D microstructures in SAG-HVPE. CrystEngComm 20 6207-6213.

[35] Avit G, André Y, Bougerol C, Castelluci D, Dussaigne A, Ferret P, Gaugiran S, Gayral B, Gil E, Lee Y, Ramdani M R, Roche E and Trassoudaine A 2016 GaN Rods Grown on Si by SAG-HVPE toward GaN HVPE/InGaN MOVPE Core/Shell Structures. Cryst. Growth Des. 16 2509-2513.

[36] Zeghouane M 2019 Controle de l'homogénéité et de la composition en indium dans les nanofils InGaN 
synthétisés par HVPE. PhD Thesis Université Cermont Auvergne, France.

[37] Trassoudaine A, Cadoret R and Aujol E Growth of Gallium Nitride by Hydride Vapor Phase Epitaxy, in Nitride Semiconductors: Handbook on Materials and Devices. Weinheim: Wiley-VCH, 2003.

[38] Kumagai Y, Takemoto K, Hasegawa T, Koukitu A and Seki H 2001 Thermodynamics on tri-halide vaporphase epitaxy of $\mathrm{GaN}$ and $\operatorname{In}_{\mathrm{x}} \mathrm{Ga}_{1-\mathrm{x}} \mathrm{N}$ using $\mathrm{GaCl}_{3}$ and $\mathrm{InCl}_{3}$. J. Cryst. Growth 23157. 